\title{
A BEST POSSIBLE EXTENSION OF THE HAUSDORFF-YOUNG THEOREM
}

\author{
ROBERT M. YOUNG
}

\begin{abstract}
The purpose of this note is to show that a recent result of A. M. Sedleckii on nonharmonic Fourier series in $L^{p}(-\pi, \pi)$ has as a simple consequence a "best possible" extension of the classical Hausdorff-Young theorem.
\end{abstract}

ThEOREM. Let $1<p \leqslant 2$ and let $q$ be the conjugate exponent. Let $\left\{\lambda_{n}\right\}$ be any sequence of complex numbers for which

$$
\sup \left|\lambda_{n}-n\right|<(p-1) / 2 p \quad(-\infty<n<\infty) .
$$

If $\left\{c_{n}\right\} \in l^{p}$, then there is a function $f$ in $L^{q}(-\pi, \pi)$ such that

$$
c_{n}=\hat{f}\left(\lambda_{n}\right)=\frac{1}{2 \pi} \int_{-\pi}^{\pi} f(t) e^{i \lambda_{n} t} d t
$$

If condition (1) is replaced by the weaker condition

$$
\left|\lambda_{n}-n\right|<(p-1) / 2 p,
$$

then the conclusion of the theorem is false.

Proof. Under the conditions of the theorem, there is an isomorphism of $L^{p}(-\pi, \pi)$ which maps $e^{i n t}$ into $e^{i \lambda_{n} t}$ [4]. It follows that for some constant $m>0$ and every finite sequence $\left\{a_{n}\right\}$,

$$
m\left\|\sum a_{n} e^{i n t}\right\|_{p} \leqslant\left\|\sum a_{n} e^{i \lambda_{n} t}\right\|_{p}
$$

This, together with the Hausdorff-Young theorem, shows that

$$
m\left(\sum\left|a_{n}\right|^{q}\right)^{1 / q} \leqslant\left\|\sum a_{n} e^{i \lambda_{n} t}\right\|_{p} .
$$

But the above inequality guarantees [2] that the equations in (2) are solvable for $f$ in $L^{q}(-\pi, \pi)$, and the first half of the theorem is established.

To see that condition (1) cannot be replaced by (3), let

$$
\mu_{n}= \begin{cases}n-(p-1) / 2 p, & n>0 \\ 0, & n=0 \\ n+(p-1) / 2 p, & n<0\end{cases}
$$

and choose $\left\{\lambda_{n}\right\}$ such that

Received by the editors September 30, 1976.

AMS (MOS) subject classifications (1970). Primary 42A80; Secondary 46B15.

Key words and phrases. Nonharmonic Fourier series, Hausdorff-Young theorem.

- American Mathematical Society 1977 


$$
\left|\lambda_{n}-n\right|<(p-1) / 2 p \text { and } \sum\left|\lambda_{n}-\mu_{n}\right|<\infty .
$$

Since $\left\{e^{i \mu_{n} t}\right\}_{n \neq 0}$ is complete in $L^{p}(-\pi, \pi)\left[3\right.$, p. 65], so too is $\left\{e^{i \lambda_{n} t}\right\}_{n \neq 0}[1$, p. 66]. It follows, in particular, that there is no function $f$ in $L^{q}(-\pi, \pi)$ for which $\hat{f}\left(\lambda_{n}\right)=0(n \neq 0)$ and $\hat{f}\left(\lambda_{0}\right)=1$, and the proof is complete.

\section{REFERENCES}

1. W. O. Alexander, Jr. and R. Redheffer, The excess of sets of complex exponentials, Duke Math. J. 34 (1967), 59-72. MR 34 \#6432.

2. R. P. Boas, Jr., A general moment problem, Amer. J. Math. 63 (1941), 361-370. MR 2, 281.

3. N. Levinson, Gap and density theorems, Amer. Math. Soc. Colloq. Publ., vol.26, Amer. Math. Soc., Providence, R.I., 1940. MR 2, 180.

4. A. M. Sedleckii, Equivalent sequences in certain function spaces, Izv. Vysš. Učebn. Zaved. Matematika, 1973, no. 7 (134), 85-91. MR 48 \#12021.

Department of Mathematics, Oberlin College, Oberlin, Oho 44074 